\title{
UAV and Soft Computing Methodology for Monitoring Landslide Areas (Susceptibility to Landslides and Early Warning)
}

\author{
${ }^{1 *}$ ERNESTO BERNARDO, ${ }^{1}$ ROCCO PALAMARA, ${ }^{2}$ ROGERS BOIMA \\ ${ }^{1}$ Department of civil engineering, energy, environment and materials (DICEAM) \\ Mediterranea University of Reggio Calabria \\ Via Graziella Feo di Vito - 89124, Reggio Calabria \\ ITALY \\ ${ }^{2}$ UK Economic Interest Grouping (UKEIGN) N. GEE000176 \\ 87 Hungerdown E4 6QJ London \\ UNITED KINDOM
}

\begin{abstract}
In this work, we created a map of the susceptibility to landslides in GIS environment using neural network, Analytical Hierarchy Process (AHP) multicriteria analysis method and fuzzy methodology, producing five categories (levels) of risk. Subsequently, starting from this map, we identified (fuzzy methodology) the areas of the road's network most exposed to landslide risk also using remote sensing techniques (classification and segmentation techniques) overlapped on the street map. This system therefore provides us the level of attention that affects the transport infrastructure investigated (a higher level of attention corresponds to a higher level of landslide risk). Once the risk map for a large area was identified, we focused on local monitoring of a part of it automatically selected by the GIS. The monitoring of this area was carried out through an innovative system (made by us) that allows to monitor landslide risk areas and to study landslide phenomena through the use of Unmanned Aerial Vehicles (UAVs). Specifically, with this innovative solution, data are acquired thanks to an automated system of UAVs and wireless charging platforms (capable to acquired, to transmit and to store data); subsequently, the acquired data are stored automatically in a special platform that allows us to create the point cloud and 3D models of the investigated area (which in turn they are superimposed on the digital models created in previous monitoring), also allowing the creation of the land mass displacement's sequence in a video. Finally, in relation to early warning, the system allows civil protection to be warned in the event of a landslide risk (start of new landslides or continuation of landslides that have already begun) which in this way will be able to warn the population also through social media.
\end{abstract}

Key-Words: - Landslide, Unmanned Aerial Vehicle, GIS, Susceptibility Maps, Natural Hazard, 3D Model

Received: December 23, 2020. Revised: April 20, 2021. Accepted: April 28 2021. Published: May 5,

2021.

\section{Introduction}

In Italy every year, the hydrogeological instability causes the destruction of roads, buildings, etc., causing victims and countless economic damage. The monitoring of natural hazards, the evaluation of their impact and the general risk assessment are therefore decisive steps towards the selection and sizing of adequate protection measures.

The hydrogeological instability includes the set of all geomorphological processes (from surface and sub-surface erosion, to the most catastrophic events as landslides and floods) that have a highly damaging and destructive action, of soil degradation and therefore of infrastructure damage. The causes of the hydrogeological instability are partly due to weather conditions and climatic variations but are above all anthropogenic (deforestation, excessive soil consumption, overbuilding). In Italy, the actions that can be implemented in relation to the risk of hydrogeological instability are basically: the forecast, the prevention and the mitigation of the effects.

The monitoring of natural hazards, the assessment of their impact and the general risk assessment are therefore decisive steps towards the selection and sizing of adequate protection measures. The evolutionary process of the sciences of Geomatics, which is now fundamental and transversal in the study of various engineering / architectural phenomena, is finding increasingly efficient and productive interactions with the disciplines of Soft computing. This interaction can lead to the study and production of highly performing systems in relation 
to the prevention of territorial and environmental risk and the production of maps useful for the prediction and prevention of natural hazards. The use of Unmanned Aerial Vehicle (UAV) systems is also spreading more and more thanks to their ease of use in different situations and for different applications for monitoring and preventing natural hazards. Particular attention is therefore dedicating research to the use of UAVs in this area with particular reference to the methods of automating the image acquisition process to that of flight design and recharging. Such developments may therefore open up further perspectives in the field of landslide monitoring.

This work proposes an experimental methodology for the characterization of the susceptibility to landslides in the Sicilian area through the combination of remote sensing and GIS systems and soft computing.

In particular, we created a map of the susceptibility to landslides in GIS environment, producing five categories (levels) of risk. Subsequently, starting from this map, we identified the areas of the road network most exposed to landslide risk also using road maps building through remote sensing techniques. This system provides us with the level of attention that affects the transport infrastructure investigated (a higher level of attention corresponds to a higher level of landslide risk).

Furthermore, once the risk map for a large area was identified, we focused on the local monitoring of a portion of it automatically selected by the GIS, proposing an innovative system that allows us to monitor landslide risk areas continuously and to study landslide phenomena through the use of Unmanned Aerial Vehicles (UAVs) producing an early warning system. Data are acquired thanks to an automated system of UAVs and wireless charging platforms (capable to acquire, to transmit and to store data); the acquired data are stored automatically in a special platform that allows us to create the point cloud and 3D models of the investigated area (which in turn they are superimposed on the digital models created in previous monitoring), also allowing the creation of the land mass displacement's sequence in a video. Finally, in relation to early warning, the system allows civil protection to be warned in the event of a landslide risk (start of new landslides or continuation of landslides that have already begun) which in this way will be able to warn the population also through social media.

The assessment of susceptibility to landslides is a complicated topic also due to the difficult assessment of the spatial and temporal distribution of past events for large areas, mainly due to the limitations and gaps of historical documents and geographical information. Due to these limitations, the most widely used tool for assessing susceptibility to landslides is the Geographic Information System (GIS), which allows analysing and managing a considerable amount of information.

The work presented here has the following objectives:

- Use the GIS software, the Analytical Hierarchy Process (AHP) multicriteria analysis method and soft computing techniques to create a landslide susceptibility map for the Sicilian Area through the weighted combination of various factors such as slope, lithology, elevation, rainfall and land use.

- Extract the road network (fuzzy methodology) by analysing remote sensing images superimposed on Open Street Map (remote sensing classification and segmentation techniques).

- Once the landslide susceptibility map has been obtained, determine the network infrastructures to pay more attention to.

- Use UAVs to create thematic maps (mapping studying and highlighting the characteristics of the landslide area, area of rupture, superposition of the displacements at break of the section aligned with the landslide, etc etc.).

- Monitoring the evolution of an active morphological process through a multitemporal analysis (monitoring).

- Early warning forecasting systems.

Indeed, the Geomatics Laboratory of the Mediterranean University of Reggio Calabria has launched a series of experiments in the last two years in order to create an innovative system for the study and monitoring of landslides with particular reference to the use of drones.

As for the mapping activities, the use of mini and micro-UAVs makes it possible to detect relatively modest areas (often less than 1-2 Km) in a very short time and with very competitive costs. GIS was implemented with the results collected from UAV surveys.

In the field of geo-hydrological instability this application can be considered very valid both for the detection of landslides and rock walls subject to collapse phenomena. The use of UAVs allows the production of high resolution orthophotos useful both for the realization of event maps, in which often it is 
also provided for a delimitation of the area affected by the instability and a possible mapping of the main morphological elements that characterize; and for the creation of digital models of landslides [1-11].

In this work we intend to present an innovative system that allows you to monitor landslide risk areas and study landslide phenomena (already underway) through the use of UAVs. The data is acquired thanks to an automated system of UAVs and wireless charging platforms (capable of acquiring, transmitting and storing data); the acquired data are stored automatically in a special platform that allows you to create the point cloud and 3D models of the investigated area, which in turn are superimposed on the digital models created in previous monitoring, also allowing the creation of a video of the sequence of displacement of the land mass. Finally, with a view to early warning, the system allows civil protection to be warned in the event of a landslide risk (start of new landslides or continuation of landslides that have already begun) which in this way will be able to warn the population through social media (Fig.1).

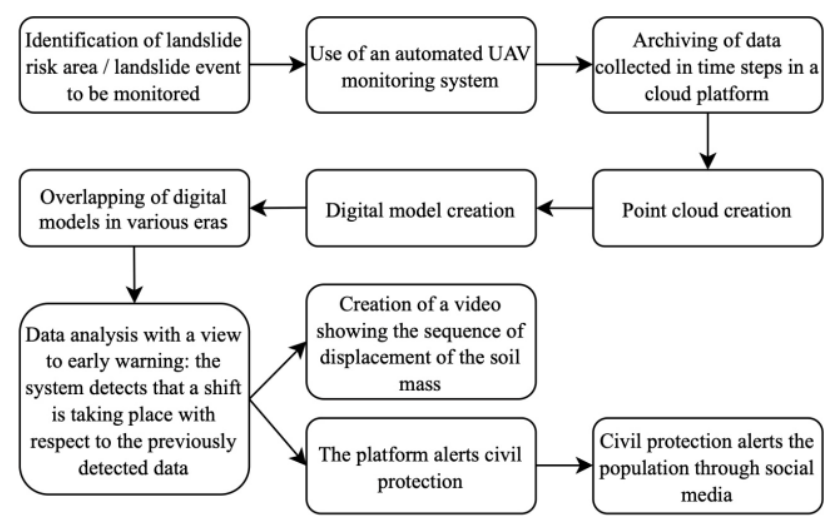

Figure 1 - Operation diagram of the monitoring system.

\section{Materials and Methods}

\subsection{Innovative measuring system}

In this work we used a fleet of automated UAVs connected to the cloud (or to a local network) which are automatically recharged through special charging stations located in predetermined points. The drone fleet sends data in real time to the cloud platform, which is then processed by the algorithms to select the images.

The data acquisition system provides for the installation of two platforms along the path to be monitored to allow the drone battery to be recharged and the data necessary for subsequent processing to be transferred.
We have built an innovative monitoring system including drones, intelligent multi-landing and charging pads, automatically governed that communicate at short range with nearby drones and indicate the status of the station.

1. When an UAV in flight detects that the battery is running low, it looks for the nearest charging station, the latter communicates to the drone if there is a free pitch and a charged battery available.

2. Having obtained the ok to land, the drone, knowing the GPS coordinates of the station, approaches and, moving vertically, lands on the assigned stand.

3. Once landed, a subsystem recharges the onboard battery or swaps it, replacing the discharged battery with a charged one. During the replacement, the drone is still powered through a special connector in order not to lose communications and to allow the automatic procedure with the exchange of information. After recharging, take-off takes place.

The wireless charging station is composed of an "intelligent" induction plate which, when the drone lands, determines the type of batteries supplied to the aircraft, and thus establishes the correct charging parameters. This is made possible thanks to a small device installed on board the drone, consisting of a microcircuit with a data transmission system, weighing a few tens of grams and dimensions contained in the order of a few centimeters (so that it can be installed not only on large professional UAVs but also on smaller commercial ones) that when the drone lands on the "smart" plate it communicates the type of battery mounted on the drone.

These stations are totally waterproof and weatherproof and also serve as a temporary shelter for the appliances (Fig.2).

In detail, we realized a mini light-weight unattended drone system, including a C500 charging pad, a charging landing gear, a tailored Mavic 2/2 Pro battery, a canopy, an OC (Embedded AIcomputer), a LS (local server), an CS (internet server), a T3 (HDMI camera monitoring), a loudspeaker and a DJI Mavic 2 Pro (Fig.2a).

The drones used are DJI Mavic 2 Pro (Fig.2b), equipped with omnidirectional vision sensors and infrared sensors, obstacle detection system, intelligent features such as Hyperlapse, Point of Interest, ActiveTrackTM 2.0, TapFly and 
QuickShots, as well as assisted piloting systems (APAS).

Mavic 2 Pro is equipped with a fully stabilized threeaxis gimbal camera, with a 1-inch CMOS sensor to record $4 \mathrm{~K}$ videos and take 20 -megapixel photos, reducing the angular vibration range to $\pm 0.01^{\circ}$.

In particular, the process of this application is divided into two phases:

1. Definition of flight plan, in terms of GSD (Ground Sampling Distance), image overlay and waypoint route: The images are captured following a waypoint path set by the designer. The GSD (Ground Sampling Distance) define the flight height considering the required definition ( $\mathrm{cm} /$ pixel); the time to capture images is determined to avoid overlaps and then survey areas that have already been processed.

2. Transmission of the data collected in temporal phases in a cloud platform where the point cloud and the digital model will subsequently be created.
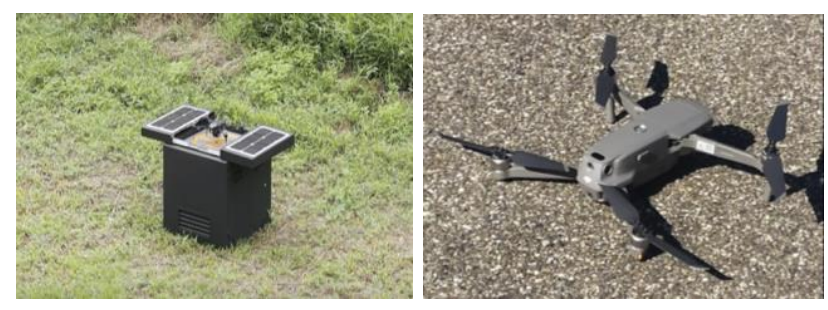

Figure 2 - UAV (a) and charging station (b).

\section{Study area}

In Sicily hydrogeological instability is widespread and represents a problem of considerable importance due to the geological and geomorphological conformation of the territory, characterized by a complex orography and small hydrographic basins, which have extremely rapid response times to precipitation (the time between the beginning of the rain and the occurrence of the flood in the stream is very short). Intense meteorological events, combined with these characteristics of the territory, can therefore give rise to violent alluvial phenomena characterized by very rapid kinematics (mudslides and flash floods).

The hydrogeological risk is also strongly conditioned by the action of man. The density of the population present in hydrogeological risk areas, unauthorized buildings, the abandonment of mountain land, fires, lack of maintenance of the slopes and waterways, aggravate the instability and further highlight the fragility of the Sicilian territory by increasing exposure to phenomena and therefore the risk itself.

In Sicily, the Regional Basin Authority identifies areas at hydrogeological risk.

In relation to the specific analysis of critical areas highlighted in the previous analysis, in order to produce a continuous monitoring and early warning system useful for civil protection, we focalized the attention on two areas:

- to the HIMERA viaduct on the A19 PalermoCatania motorway, a landslide dating back to 2015 that broke a pillar of the Himera viaduct (Fig.3). This highway, finally after 5 years is working again.

- the Reginella Landslide, which blocked the connection between two mountain villages by completely isolating them (Fig.4).

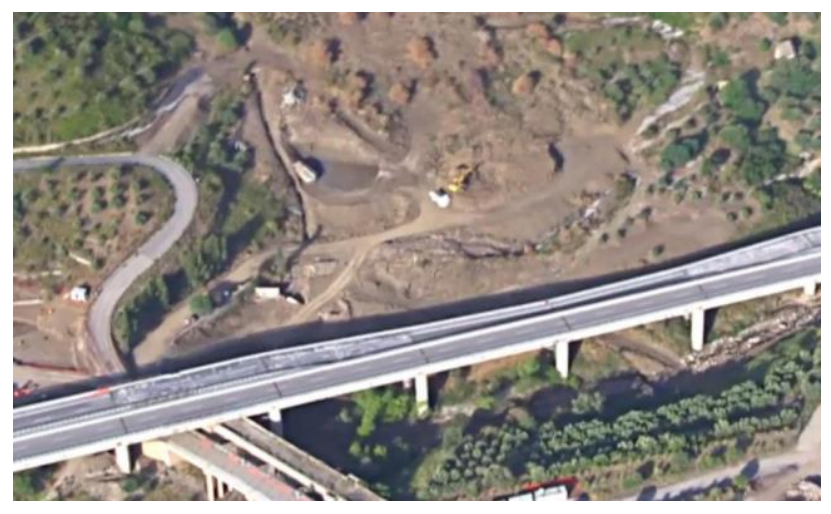

Figure 3 - Landslide close to the HIMERA viaduct.

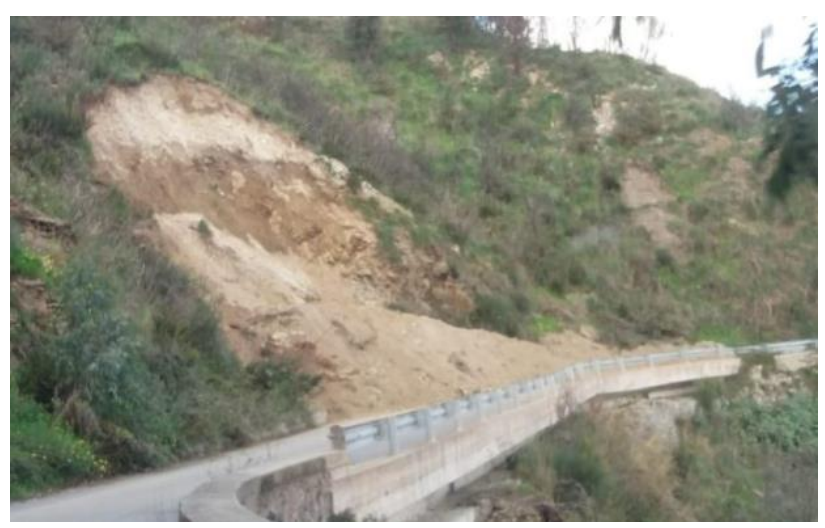

Figure 4 - Reginella Landslide

\subsection{GIS layer structure}

In order to produce a landslide susceptibility map based on the soft computing methodology and Analytical Hierarchy Process (AHP) multicriteria analysis, the following input data were used which were acquired from:

- The Hydrogeological Plan (PAI) (Figs.5, 6) (containing landslides occurred in the past, 
together with an assessment of areas with a future potential risk of landslide, but without an estimate of the annual probability of occurrence).

- Remote sensing data produced through the classification and segmentation of images using OBIA and traditional pixel based techniques (Fig.7, 8).

- UAV Data survey.

- Vector and raster layers and derived maps (DEM, Remote Sensing images (Google Earth), Rainfall Map, Elevation Map, Lithology Map, Land use Map, Slope Map).

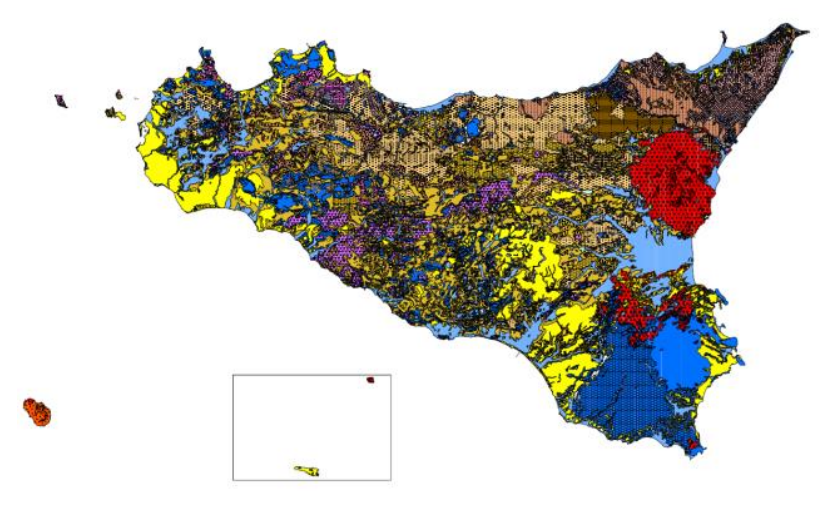

Figure 5 - Lithological maps.

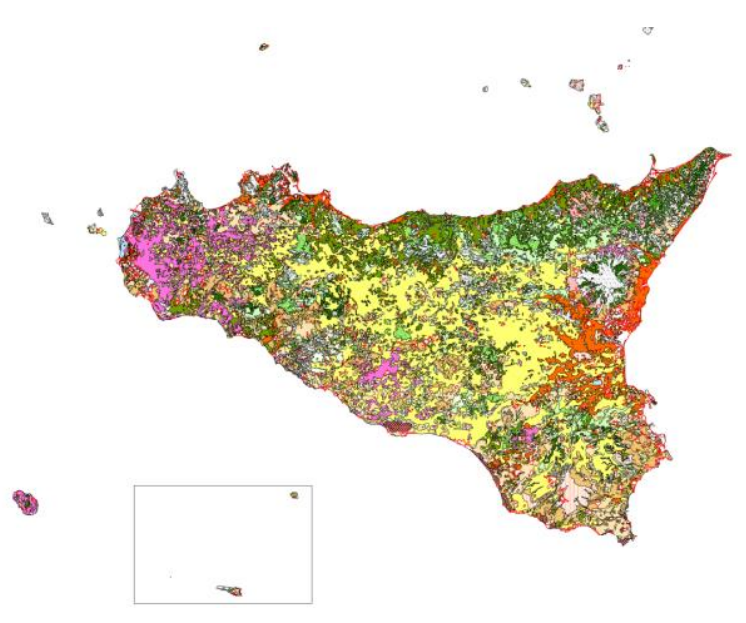

Figure 6 - Land Use

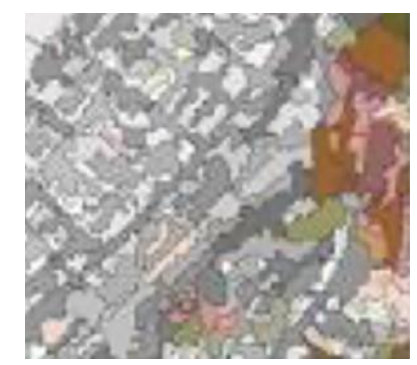

Figure 7 - Classification of satellite images

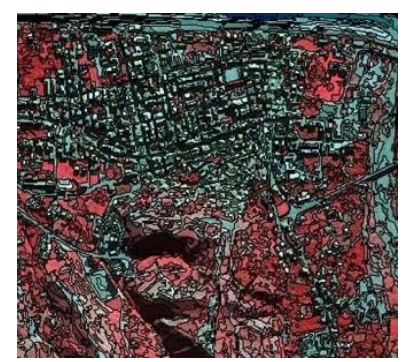

Figure 8 - Segmentation with pixel visibility

The GIS was created by overlapping several layers (raster and vector). In particular, the raster layers are related to: DEM, Precipitation map, Elevation map, Lithology map, Land use map, Slope map and Contour lines. The level curves used as vector layers are obtained from our detected three-dimensional model, subsequently vectorized and transferred to our GIS, comparing them between scenario 1 and scenario 0 , so as to be able to make measurable the displacement that is occurring on the collapsed body.

The objective of this work is to create a landslide susceptibility map through the weighted combination of various indices based on the values reached by the characteristic factors in the landslide areas highlighted in the PAI and on the further evaluation of the factors through the soft computing techniques that allow to predict indices and weights useful to calculate the different study area susceptibility. The calculated indices refer to factors such as slope, lithology, and land use. The landslide susceptibility values obtained were divided into five classes: very low, low, moderate, high, very high. The resulting network infrastructures that are particularly relevant during the emergency and which require plans to reduce the risk of landslides were highlighted by overlapping the main network infrastructures obtained from segmentation and classification of remote sensing data on the landslide susceptibility map obtained soft computing techniques and the use of fuzzy logic and "if-then" [10-17].

\subsection{Landslide susceptibility map}

The assessment of landslide susceptibility can be complicated because it is very difficult to assess both the space and the temporal distribution of past events for large areas mainly due to limitations and gaps in both historical records and geographical information. The landslide susceptibility assessment can be considered as the first step towards a hazard and risk assessment.

In the proposed study, areas with different classes of landslide susceptibility are market with different 
colours (from green, which indicates a very low susceptibility, to red, which stands for a very high susceptibility).

To produce the landslide susceptibility map, a total of 5 inputs were selected for the model, considering the main characteristics of the landslides: slope, lithology, elevation, rainfall and land use. Each factor was characterized in classes whose weight was determined on the basis of the relevance resulting from the analysis of the map of landslide areas identified by the PAI and from the remote sensing images. The weight of each class (Table 1) was determined by the neural network that allows to predict weight's values through the interconnection of different input data; this procedure is based on historical series data acquired on the same data and from the parameters behavior measured in similar events occurred during the time (same land typology, land lithology, kind of landslide, land use, and vegetation presence). The importance of the five factors were instead determined using the Analytical Hierarchy Process (AHP) multicriteria analysis method, considering the slope, the elevation, the precipitation as the main factors. The resulting index was finally obtained (Table 2) by multiplying the weight of each class of factors and the weight of the same factor collected by the AHP model.

Table1 - Characteristic factors weights.

\begin{tabular}{ccc|ccc}
\hline Factor & Factor class & Weight & Factor & Factor class & Weight \\
\hline \multirow{4}{*}{ SLOPE } & $<8^{\circ}$ & 0.32 & & $<850$ & 0.31 \\
& $9-15^{\circ}$ & 0.28 & \multirow{2}{*}{ RAINFALl } & $850-1200$ & 0.27 \\
& $16-25^{\circ}$ & 0.24 & & $1200-1800$ & 0.24 \\
& $>26^{\circ}$ & 0.21 & & $>1800$ & 0.010 \\
\hline \multirow{2}{*}{ LAND USE } & Forests & 0.11 & & Rocks & 0.27 \\
& Rural areas & 0.74 & UTHOLOGY & Clays and sand stones formations & 0.62 \\
& Superficial areas & 0.14 & & Flysch & 0.18 \\
\hline \multirow{4}{*}{ ELEVATION } & $0-150$ & 0.28 & & & \\
& $151-300$ & 0.33 & & & \\
& $301-600$ & 0.30 & & &
\end{tabular}

Table2 - Resulting index.

\begin{tabular}{|c|c|c|c|c|}
\hline & & $\begin{array}{l}\text { Class } \\
\text { weight }\end{array}$ & $\begin{array}{l}\text { Factors } \\
\text { weight }\end{array}$ & $\begin{array}{c}\text { Resulting } \\
\text { index }\end{array}$ \\
\hline \multirow{4}{*}{ SLOPE } & $<8^{\circ}$ & 0.32 & \multirow{4}{*}{0,41} & 0.13 \\
\hline & $9-15^{\circ}$ & 0.28 & & 0.11 \\
\hline & $16-25^{\circ}$ & 0.24 & & 0,01 \\
\hline & $>26^{\circ}$ & 0.21 & & 0,009 \\
\hline \multirow{3}{*}{ LAND USE } & Forests & 0.11 & \multirow{3}{*}{0.03} & 0.003 \\
\hline & Rural areas & 0.74 & & 0.022 \\
\hline & Superficial areas & 0.14 & & 0,004 \\
\hline \multirow{4}{*}{ ELEVATION } & $0-150$ & 0.28 & \multirow{4}{*}{0.28} & 0.007 \\
\hline & $151-300$ & 0.33 & & 0.009 \\
\hline & $301-600$ & 0.30 & & 0.008 \\
\hline & $>601$ & 0.10 & & 0.003 \\
\hline \multirow{4}{*}{ RAINFALL } & $<850$ & 0.31 & \multirow{4}{*}{0.18} & 0.056 \\
\hline & $850-1200$ & 0.27 & & 0.048 \\
\hline & $1200-1800$ & 0.24 & & 0.043 \\
\hline & $>1800$ & 0.010 & & 0.002 \\
\hline \multirow{3}{*}{ UTHOLOGY } & Rocks & 0.27 & \multirow{3}{*}{0.04} & 0.010 \\
\hline & Clays andsandstones & 0.62 & & 0.025 \\
\hline & Flysch & 0.18 & & 0.007 \\
\hline
\end{tabular}

For the landslide susceptibility map (Fig. 10), we used the neural network to predict the behaviour of the individual actions. We have given as input the climatic events such as rainfall, temperature changes, any fires that have occurred in the area, any anthropic activities in the area, corrivation phenomena.

The data obtained for the assessment of susceptibility were classified into five categories: Very low, Low, Moderate, High, Very high. According to the results, $22 \%$ of the study area is classified as very highly susceptible, $36 \%$ as highly susceptible, $20 \%$ as moderately susceptible, $17 \%$ as lowly susceptible and $5 \%$ as very low susceptible (Table 3, Fig.9).

Table 3 Landslide susceptibility evaluation

\begin{tabular}{|c|c|}
\hline Lanslide Susceptibility & Index \\
\hline Very low & 0,062 \\
\hline Low & 0,164 \\
\hline Moderate & 0,201 \\
\hline High & 0,375 \\
\hline Very High & 0,227 \\
\hline
\end{tabular}

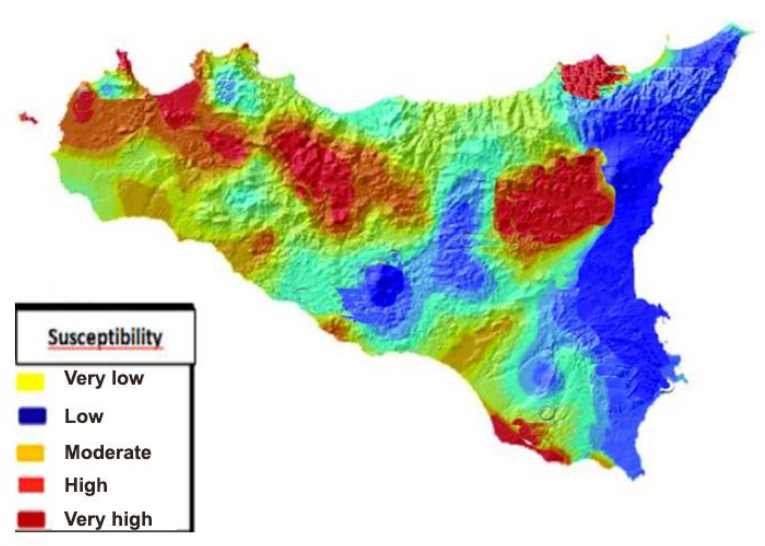

Figure 9 - Landslides susceptibility map.

The results mentioned above show that $64 \%$ of the entire territory of the province is affected by a strong landslide susceptibility value. From the map obtained (Fig.6) it is possible to note that the high and very high susceptibility are the hills, that is, the areas between the coasts and the central part of the province. These areas are particularly relevant for the connections within the various internal urban areas 
and the main inhabited centres and services located along the coasts. Furthermore, the landslide susceptibility assessing procedure adopted is in accordance with the work carried out by the Sicilian Region Basin Authority: $75 \%$ of the areas with high and very high susceptibility coincide with the landslide areas identified by the PAI maps.

\subsection{Lifelines for transport}

The lifelines are the networks, which are developed throughout the territory to connect the various settlements and points of interest of the various subsystems. They guarantee the essential services necessary for the functioning and survival of communities (transport, telecommunications, energy, water and health networks). We can define them as the set of structures, infrastructures and services indispensable for a given maintenance of the systems and/or life protection. The engineering of the guidelines must not refer exclusively to natural disasters, such as earthquakes, but in general, to any type of emergency due to a generic human or natural danger or disaster: meteorological or water, geological events, fires, floods, toxic and industrial accidents, transport of materials. To design, adopting the criteria for the maintenance of lifelines means having greater guarantees of reliability and efficiency in any emergency condition [18-22].

These aspects of infrastructure design and management have come to the attention of the public with greater interest only in recent years.

Recent experiences have highlighted the extreme importance of the functioning of lifelines (networks throughout the territory connecting settlements and points of interest with essential services necessary for the functioning and survival of communities) in the emergency conditions following a catastrophic event.

Some lifelines must ensure effectiveness and efficiency immediately after the disaster, in some cases it must be maintained during the event, to allow rapid and efficient access and assistance and rescue, guarantee evacuation and more generally maintain access to all emergency services [23-27].

\subsection{Lifelines for road transport}

The Sicilian road network consists of $570 \mathrm{~km}$ of highway, $3.591 \mathrm{~km}$ of statal road and other 16.660 among Municipality, province and other (Fig.10). Road use varies with seasonal activities, and the variability is particularly significant in tourist attraction areas.
The strategic roads, which are the backbone of the transport lifelines, have been classified according to the flow of traffic, population served and relevance in the national and regional transport system (Fig.11).

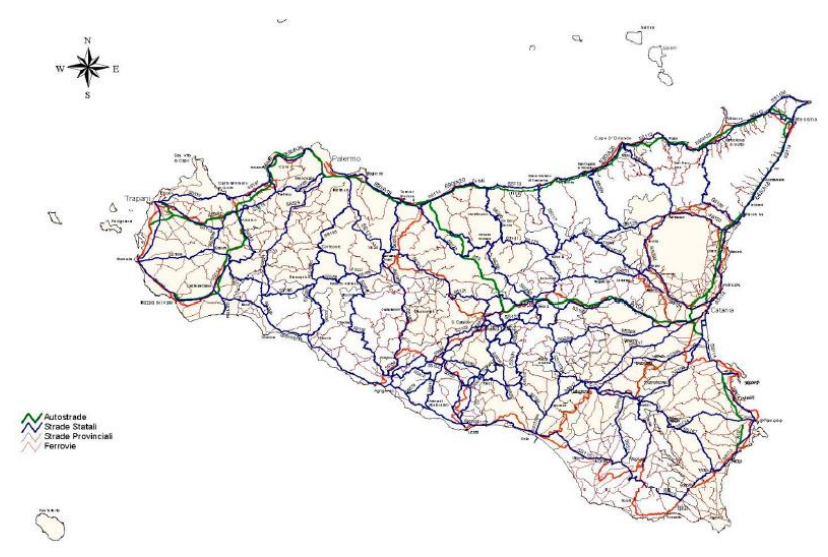

Figure 10 - Principal road networks.

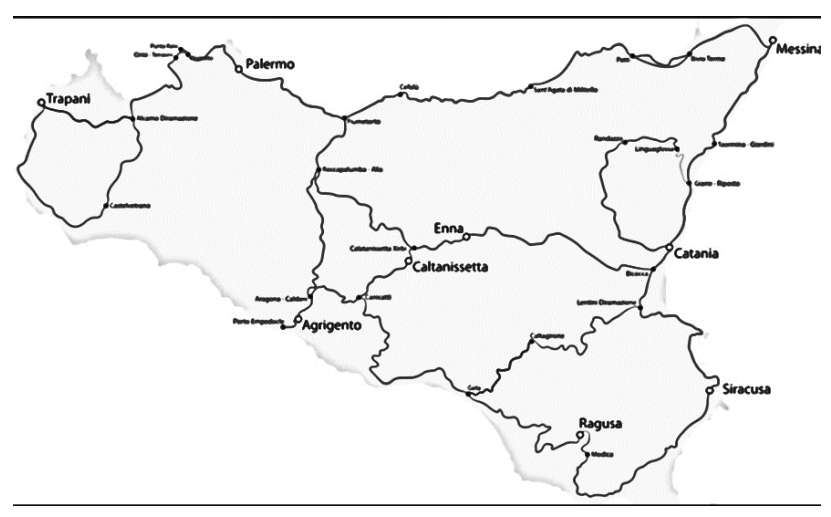

Figure 11 - Road network considered.

This classification of the importance of the primary transport Sicilian network is based on the level of service in the event of a disaster, the traffic flows and the population served, defining three sets (Fig.8): (i) strategic transport; (ii) transversal access routes; (iii) secondary transport routes.

We created a map from satellite imagery quickly extracting roads with Remote Sensing techniques, through the Object Based Image Analysis (OBIA), with a segmentation that starts from concepts of Mathematical Morphology. We superimposed it in GIS on the Open Street Map layers.

The main purpose of this study is to identify the stretches of road network considered exposed to landslide danger starting from the susceptibility map. This is obtained with the application of soft computing techniques (neural network and fuzzy logic) to have the landslide susceptibility layer and 
the image constructed with remote sensing and OSM superimposition techniques. Then a Fuzzy logic system with 2 inputs, 15 "if - then" and 1 output representing the "attention level" has been implemented in Matlab Environment. Fifteen "ifthen" fuzzy rules were set to evaluate the "level of attention", according to the following logic [28-33]:

- If the "susceptibility" is LOW and the "infrastructural relevance" is MODERATE, the "level of attention" is LOW.

- If the "susceptibility" is MODERATE and the "relevance of the infrastructure" is MODERATE, then the "level of attention" is HIGH.

- If the "susceptibility" is HIGH and the "infrastructure relevance" is MODERATE, then the "level of attention" is HIGH.

Fig. 12 shows the results of the road network considered exposed to landslide danger starting from the susceptibility map using soft computing technique.

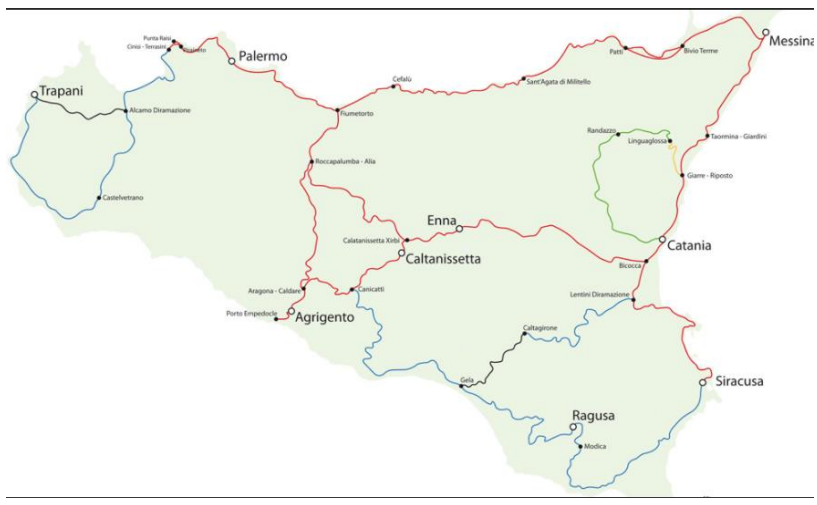

Figure 12 - Level of attention of the road infrastructures resulting from the analysis.

\subsection{UAV Survey (specific landslide monitoring)}

Once the susceptibility map has been built, it is possible to automatically select a particular study area via GIS in order to monitor it over time both for the evaluation of the space-time evolution of the landslide and for the production of warning systems for civil protection. The proposed methodology obviously refers to the use of UAVs.

In particular, the availability of images acquired in different eras (generated with the monitoring system described above) useful for the automatic creation of 3D space-time models and consequent extrapolation of the contour lines (Fig.13 relating to the Himera Viaduct) allowed an estimate of the displacements and speeds surface at breakage of the collapsed effusion (Fig.14 relating to the Reginella Lanslide) [34-39].

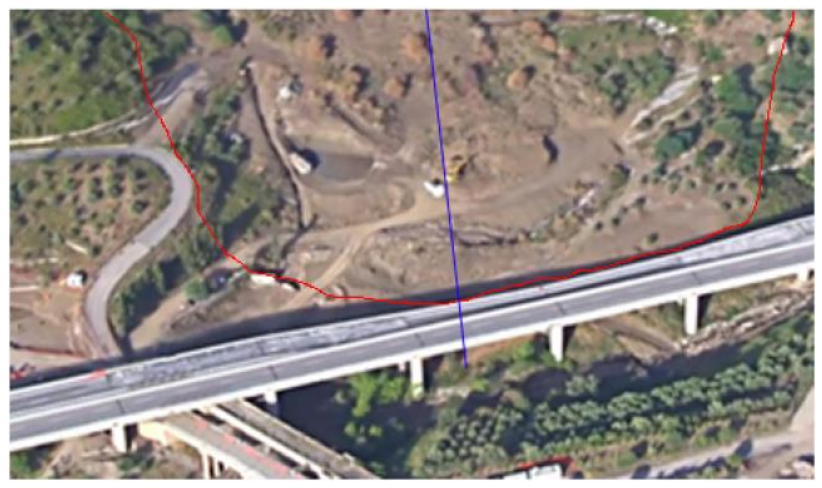

Figure 13 - Orthophoto returned by UAV with delimitation of the landslide area (in magenta), representation of the contour lines (in red) and indication of the section considered (in blue) for the evaluation of displacements. Example applied on Himera viaduct.

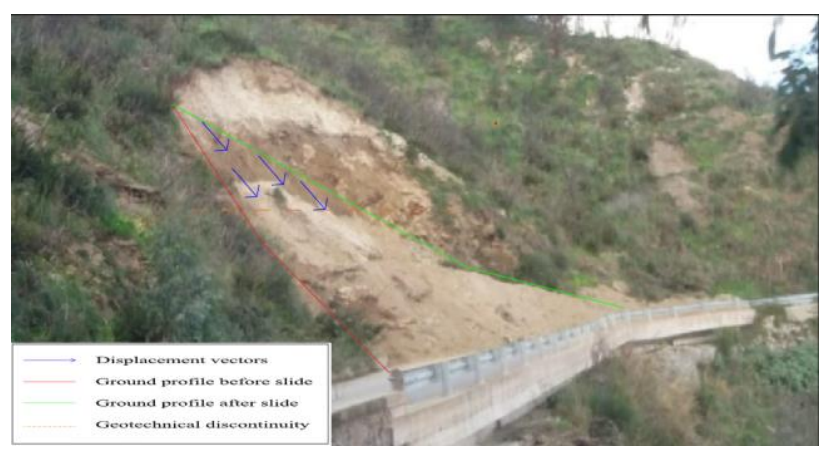

Figure 14 - Superposition of the displacements at break of the section aligned with the landslide.

Example applied on the Reginella Landslide.

The proposed system can also be used for fast early warning (comparison between two-point clouds of two surveys at different instants). In this way, a UAV would play a dual role, providing both to carry out the photographic documentation necessary to define the geometry and to detect the displacements of the ground and compare them with the values calculated at break: by sending an alarm signal in case of agreement and warning the protection civil in case of landslide risk (beginning of new landslides or continuation of landslides already started) which in turn can warn the population through social media.

The displacements calculated at break will be accessible via the Web, through the dedicated platform.

Furthermore, the proposed system allows to calculate the deformed mesh of a slope in different 
instants of time, useful for carrying out a slope stability analysis with the Finite Differences Method (FDM).

Finally, the automatic superposition of the digital models obtained in the various eras and the superimposition of the outputs of the calculation on the photographs of the slope allows the user to have an integrated multimedia environment on the Web in which the dynamic evolution of the landslide is made immediately visible through a video of the sequence of displacement of the soil mass [40-42].

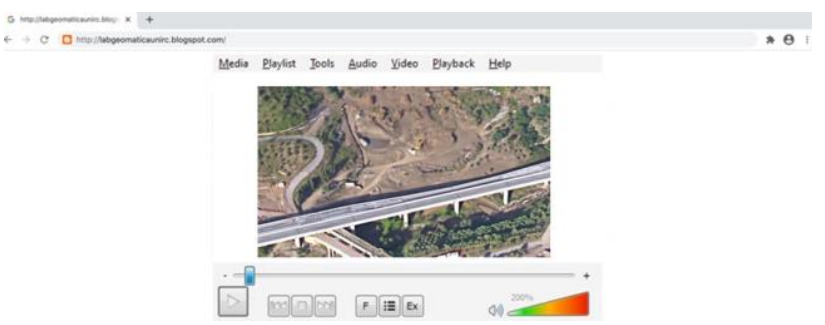

Figure 15 - Frame from the video Himera viaduct example.

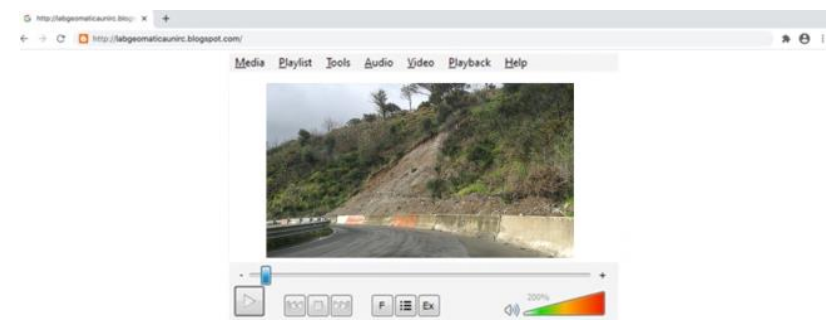

Figure 16 - Frame from the video, Reginella landslide example.

A comparison was made between the results obtained from the monitoring carried out with the proposed GIS / UAV system and the results obtained from a traditional monitoring system based on the measurement of the displacements of points on the landslide and of stable points on areas not subject to landslides. This traditional monitoring was carried out through the installation of a robotic total station that measured the variations (the displacements obtained) in these stakes over time.

Clearly from an operational, practical and visual point of view, the monitoring obtained by our system is much more intuitive and useful, as it is no longer based on a single point but on the entire area. In fact, we can compare the entire level curves of the area to scenario 0 and scenario $\mathrm{n}+1$

\section{Discussion}

The scientific literature published so far has led to the study and implementation of highly performing systems in relation to the prevention of territorial and environmental risk. The use of UAVs (Unmanned Aerial Vehicles) is still little exploited, despite the simplicity of use in different situations and for applications in the monitoring and prevention of natural hazards. Overall, the solutions adopted so far are limited to the simple achievement of a few specific results and often require the intervention of one or more operators. Our solution, on the other hand, differs from all the others, focusing on the automation processes of the various phases; on the combination of various technologies of Geomatics, Soft Computing, GIS; on the methods of dissemination of the multiple results obtained; and on possible methods to alert the population in case of danger. In order to provide a valid, complete and automated tool for the prevention of territorial and environmental risk and for early warning.

\section{Conclusion}

From the results obtained (Figs.15, 16) it is possible to note that the most relevant roads in terms of connection, such as the A19 motorway, and the other roads that connect the mountain village are those that indicate the highest level of attention. This result highlights the weaving of the network system of the province of the Sicily. Many of the infrastructures corresponding to a high level of attention, in fact, constitute the only link for very large areas. The analysis carried out highlights how impracticable the interventions, both active and passive, are to mitigate the level of risk on the identified lifelines, highlighting that the infrastructures represent the only way to reach the areas affected by a natural hazard and to provide the first aid to the population.

Currently there are many tools for monitoring landslides or landslide risk areas (sensors, cameras, etc.), the use of the UAV, however, is still little exploited. In this work we wanted to demonstrate that remotely piloted vehicles can prove to be a very useful tool in order to monitor landslide risk areas, study landslide phenomena more accurately or as a possible new expeditious method for early warning. In the near future, research will focus on improving the platform created.

\section{References:}

[1] Farina P., Rossi G., The use of multi-copter drones for landslide investigations, $3^{\text {rd }}$ North American Symposium on Landslides, 2014. 
[2] Godone D., Allasia P., Borrelli L., Gullà G., UAV and Structure from Motion Approach to Monitor the Maierato Landslide Evolution, Remote Sens., 12, 2019, 1039.

[3] Ma S., Xu C., Shao X., Zhang P., Liang X, Tian, Y., Geometric and kinematic features of a landslide in Mabian Sichuan, China, derived from UAV Photography, Landslides, 16, 2019, pp. 373-381.

[4] Barrile V., Candela G., Fotia A., Bernardo E., UAV Survey of Bridges and Viaduct: Workflow and Application. Lecture Notes in Computer Science (including subseries Lecture Notes in Artificial Intelligence and Lecture Notes in Bioinformatics), Vol.11622, 2019, pp. 269-284. https://doi.org/10.1007/978-3-030-24305-0_21

[5] Saad A.M., Tahar K. N., Identification of rut and pothole by using multirotor unmanned aerial vehicle (UAV). Meas. J. Int. Meas. Confed. 2019, 137, 2019, pp. 647-654.

[6] Setlak L., Kowalik R., Identification of Small Unmanned Flying Objects, International Journal of Circuits, Systems and Signal Processing, Vol. 14, 2020, pp. 7-12.

[7] Fesenko H., Kharchenko V., Bardis N., Kor A., Brezhniev Y., Drone Fleet Survivability Evaluation Based on Lanchesterís Modified Deterministic Model, International Journal of Circuits, Systems and Signal Processing, Vol. 14, 2020, pp. 775-781.

[8] Rossi G., Tanteri L., Tofani V. et al., Multitemporal UAV surveys for landslide mapping and characterization, Landslides, Vol.15, 2018, pp. 1045-1052. https://doi.org/10.1007/s10346-018-0978-0.

[9] Zeybek M., Serkan B., Road Distress Measurements Using UAV, Turk. J. Remote Sens. GIS, 1, 2020, pp. 13 - 23.

[10] Barrile V., Bilotta G., Self-localization by laser scanner and GPS in automated surveys. Lecture Notes in Electrical Engineering, 307, 2014, pp. 293-311.

[11] Barrile V., Meduri G.M., Bilotta G., Experimentations and integrated applications laser scanner/GPS for automated surveys WSEAS Transactions on Signal Processing, 10, 1, 2014, pp. 471-480, Doi: https://doi.org/10.1016/j.rse.2006.03.001

[12] Carrara A., Cardinali M., Detti R., Guzzetti F., Pasqui V., Reichenbaeh P., GIS techniques and statistical models in evaluating landslide hazard, Earth surface processes and landforms, 16 1991, pp. 427-445.

[13] Mersha, T., Meten, M. GIS-based landslide susceptibility mapping and assessment using bivariate statistical methods in Simada area, northwestern Ethiopia, Geoenviron Disasters, 7, 20, 2020. https://doi.org/10.1186/s40677-02000155-x.

[14] Barrile V., Bilotta G., D'Amore E., Meduri G.M., Trovato S., Structural modeling of a historic castle using close range photogrammetry, International Journal of Mathematics and Computers in Simulation, 10, 2016, pp. 370-380.

[15] Casagli N., Cigna F., Bianchini S., Hölbling D., Füreder P., Righini G., Del Conte S., Friedl B., Schneiderbauer S., Iasio C., Vlcko J., Greif V., Proske H., Granica K., Falco S., Lozzi S., Mora O., Arnaud A., Novali F., Bianchi M., Landslide mapping and monitoring by using radar and optical remote sensing: Examples from the ECFP7 project SAFER, Remote Sensing Applications: Society and Environment, Vol.4, 2016, pp. 92 - 108, ISSN 2352-9385, https://doi.org/10. 1016/j.rsase.2016.07.001.

[16] Shahabi H., Hashim M., Landslide susceptibility mapping using GIS-based statistical models and Remote sensing data in tropical environment, Sci Rep. Vol. 5, 2015, pp. 9899. https://doi.org/1038/srep09899.

[17] Postorino, M.N., Barrile, V., Cotroneo, F. (2006). Surface movement ground control by means of a GPS-GIS system. Journal of Air Transport Management Volume 12, Issue 6, November 2006, Pages 375-381.

[18] Mersha T., Meten M. GIS-based landslide susceptibility mapping and assessment using bivariate statistical methods in Simada area northwestern Ethiopia, Geoenviron Disasters, Vol. 7, 2020, 20 https://doi.org/10.1186/s40677020-00155-x.

[19] Barrile V., Fotia A., Bernardo E., Bilotta G. Road Cadastre an Innovative System to Update Information, from Big Data Elaboration. In: Gervasi O. et al. (eds) Computational Science and Its Applications - ICCSA 2020. ICCSA 2020. Lecture Notes in Computer Science. Springer, Cham. Vol. 12252. https://doi.org/10.1007/978-3-030-58811-3_51.

[20] Barilla D., Leonardi G., Puglisi A., Risk Assessment for Hazardous Materials Transportation, Applied Mathematical Sciences, Vol.3, 2009, pp. 2295-2309.

[21] Chang S.E., Nojima N., Measuring post-disaster transportation system performance: the 1995 Kobe earthquake in comparative perspective, Transportation Research Part A: Policy and Practice, 35, 2001, pp. 475- 494. 
[22] Cirianni F., Fonte F., Leonardi G. Scopelliti F. Analysis of lifelines transportation vulnerability, Procedia-Social and Behavioral Sciences, 53, 2012, pp. 29-38.

[23] C. Huang, R. Abu Al-Rub, E. Masad, and D. Little, Threedimensional simulations of asphalt pavement permanent deformation using a nonlinear viscoelastic and viscoplastic model, $J$. Materials in Civil Engineering, Vol. 23, 2011, pp. 56-68.

[24] L. A. Al-Khateeb, A. Saoud, and M. F. AlMsouti, Rutting Prediction of Flexible Pavements Using Finite Element Modeling, Jordan, J. Civil Engineering, Vol. 5, No.2, 2011, pp. 173-190.

[25] S. Pandey, K. R. Rao, and D. Tiwari, Effect of geogrid reinforcement on critical responses of bituminous pavements, 25th ARRB Conf., 2012.

[26] Y. Sari, P. B. Prakoso, A. R. Baskara, Application of neural network method for road crack detection, TELKOMNIKA, Telecommunication, Computing, Electronics and Control, Vol. 18, No.4, 2020, pp. 19621967.

[27] A. Mancini, E. S. Malinverni, E. Frontoni, P. Zingaretti, Road pavement crack automatic detection by MMS images, 21st Mediterranean Conference on Contro and Automation, Chania, 2013, pp. 1589-1596, Doi: 10,1109/MED.2013. 6608934.

[28] Z. Florkov, L. Duris, M. Veselovsky, S. Sedivý and D. Kovalova, Three-dimensional mobile mapping system and its use in road engineering, MATEC Web Conf., Vol.196, No.0408 2, 2018, Doi:https://doi.org/10.1051/matecconf/2018196 04082.

[29] H. Majidifard, P. Jin, Y. Adu-Gyamfi, W. G. Buttlar, Pavement Image Datasets: A New Benchmark Dataset to Classify and Densify Pavement Distresses. Transp. Res. Rec. J. Transp. Res. Board, 2674, 2, 2020, pp. 328-339.

[30] R. Roberts, L. Inzerillo, G. Mino, Developing a framework for using Structure-from-Motion techniques for Road Distress applications. Eur. Transp. Transp. Eur., 77, 2020, pp. 1-11.

[31] Barrile V., Ciarrani F., Leonardi G., Palamara R., A fuzzy based methodology for Landslide Susceptibility Mapping, 2nd International Symposium "New Metropolitan perspectives"Strategic Planning, spatial planning, economic programs and decision support tools, through the implementation of Horizon 2020. ISTH2020, Reggio Calabria (Italy), 2016.

[32] Beaula T., PARTHEBAN, J., Risk Assessment of Natural Hazards in Nagapattinam District
Using Fuzzy Logic Model, International Journal of Fuzzy Logic Systems, 3, 2013, pp. 2737.

[33] Zadeh L. A., Fuzzy sets. Information and control, Vol.8, 1965, pp. 338-353.

[34] Zadeh L. A., Similarity relations and fuzzy orderings. Information sciences, Vol. 3, 1971, pp. 177-200.

[35] Zlateva P., Pashova L., Stoyanov K., Fuzzy logic model for natural risk assessment in SW Bulgaria, 2nd International Conference on Education and Management Technology, Singapore: IACSIT Press, Vol. 13, 2011.

[36] Ilanloo M., A comparative study of fuzzy logic approach for landslide susceptibility mapping, using GIS: An experience of Karaj dam basin in Iran, Procedia - Social and Behavioral Sciences, 19, 2011, pp. 668-676.

[37] Bernardo E., Bilotta G. Monumental Arc 3D Model Reconstruction Through BIM Technology. In: Bevilacqua C., Calabrò F., Della Spina L. (eds) New Metropolitan Perspectives. NMP 2020. Smart Innovation, Systems and Technologies. Springer, Cham. Vol.178, 2020. https://doi.org/10.1007/978-3030-48279-4 148

[38] R. Roberts, L. Inzerillo, G. Mino, Di Exploiting Low-Cost 3D Imagery for the Purposes of Detecting and Analyzing Pavement Distresses, Infrastructures, 5, 2020.

[39] Barrile, V., Bilotta, G., Fotia, A. Analysis of hydraulic risk territories: Comparison between LIDAR and other different techniques for 3D modelling, WSEAS Transactions on Environment and Development, 14, 2018, pp. 45-52.

[40] B. Li, K.C.P. Wang, A. Zhang, Y. Fei, Automatic Segmentation and Enhancement of Pavement Cracks Based on 3D Pavement Images, J. Adv. Transp., 2019, pp. 1-9.

[41] G. Sithole, G. Vosselman, Experimental comparison of filter algorithms for bare-earth extraction from airborne laser scanning point clouds, ISPRS Journal of Photogrammetry and Remote Sensing, 2004, Vol.59, Issue 1-2, pp. 85101.

Doi:https://doi.org/10.1016/j.isprsjprs.2004.05. 004.

[42] X. Yu, J. Hyyp p, H. Kaartinen, H. Hyyppaä, M. Maltamo, P. Röinnholm, Measuring the growth of individual trees using multitemporal airborne laser scanning point clouds. International Archives of Photogrammetry, Remote Sensing and Spatial Information Sciences. Vol. XXXV1 -3/W19, WG III/3, III/4, V/3, 2005, pp 204-208. 
[43] Bernardo E., Musolino M., Maesano M. San Pietro di Deca: From Knowledge to Restoration. Studies and Geomatics Investigations for Conservation, Redevelopment and Promotion. In: Bevilacqua C., Calabrò F., Della Spina L. (eds) New Metropolitan Perspectives. NMP 2020. Smart Innovation, Systems and Technologies. Springer, Cham. Vol.178, 2020. https://doi.org/10.1007/978-3-030-482794_147

[44] Barrile V., Fotia A., Bernardo E., Bilotta G. (2021) Geomatic Techniques: A Smart App for a Smart City. In: Bevilacqua C., Calabrò F., Della Spina L. (eds) New Metropolitan Perspectives. NMP 2020. Smart Innovation, Systems and Technologies. Springer, Cham. Vol 178, 2020. https://doi.org/10.1007/978-3-03048279-4_200.

[45] Barrile V., Fotia A., Bernardo E., The Submerged Heritage: A Virtual Journey in Our Seabed, Int. Arch. Photogramm. Remote Sens. Spatial Inf. Sci., XLII-2/W10, 2019 pp. 17-24, https://doi.org/10.5194/isprs-archives-XLII-2W10-17-2019.

\section{Contribution of individual authors to the creation of a scientific article (ghostwriting policy)}

Author Contributions: Please, indicate the role and the contribution of each author:

Example

John Smith, Donald Smith carried out the simulation and the optimization.

George Smith has implemented the Algorithm 1.1 and 1.2 in $\mathrm{C}++$.

Maria Ivanova has organized and executed the experiments of Section 4.

George Nikolov was responsible for the Statistics.

Follow: www.wseas.org/multimedia/contributor-

role-instruction.pdf

Sources of funding for research presented in a scientific article or scientific article itself

Report potential sources of funding if there is any

\section{Creative Commons Attribution}

\section{License 4.0 (Attribution 4.0 \\ International , CC BY 4.0)}

This article is published under the terms of the Creative Commons Attribution License 4.0 https://creativecommons.org/licenses/by/4.0/deed.en US 